\title{
Construindo um ambiente de curadoria para engajar o cidadão em histórias noticiosas: um caso da metodologia ADR
}

\author{
Daniel Schneider ${ }^{1,2}$ Jano de Souza ${ }^{1}$ \\ daniels.br@gmail.com,jano@cos.ufrj.br \\ ${ }^{1}$ PESC/COPPE/Universidade Federal do Rio de Janiero, Rio de Janeiro, Brazil \\ ${ }^{2}$ DEMAT/ICE/ Universidade Federal Rural do Rio de Janiero, Rio de Janeiro, Brazil
}

DOI: 10.17013/risti.20.99-114

\begin{abstract}
Resumo: Neste artigo descrevemos o segundo ciclo de construção e avaliação do Acropolis, uma plataforma de computação social que permite aos cidadãos construir e compartilhar suas narrativas pessoais sobre histórias noticiosas complexas ou de longa duração. Resultados experimentais produzidos por meio de avaliações quantitativas e qualitativas demonstraram, através de evidências positivas, que a nossa abordagem proposta foi capaz de apoiar o envolvimento dos cidadãos na curadoria colaborativa de conteúdo de notícias. Usando a metodologia de pesquisa ADR concluímos o segundo ciclo deste estudo com um conjunto de recomendações de design para a construção de plataformas semelhantes.
\end{abstract}

Palavras-chave: Curadoria social; narrativas curadas pelo usuário; crowdsourcing; design science research

\section{Building a social curation environment to engage citizens in news stories: an ADR case}

\begin{abstract}
In this article we describe the second design and evaluation cycle of Acropolis, a social computing platform that allows citizens to build and share their personal narratives about complex or long-term news stories. Experimental results produced through quantitative and qualitative evaluations have shown, by positive evidence, that our proposed approach was able to support citizen engagement in collaborative curation of news content. By using the ADR research methodology, we concluded the second cycle of this study with a set of design recommendations for building similar platforms.
\end{abstract}

Keywords: social curation; user-curated narratives; crowdsourcing; design science research

\section{Introdução}

Curadoria social é a prática central do jornalismo-cidadão e dos sites de notícias sociais. Curadores de notícias não apenas recebem e filtram mensagens: eles selecionam 
ativamente e moldam o conteúdo, procurando notícias e engajando-se nos processos de reenquadramento e remixagem (Jenkins, Ford \& Green, 2013). Em contraste com a curadoria jornalística profissional - que baseia-se na estratégia de "empurrar" a notícia, mantendo a tomada de decisão do público leitor dentro dos limites do terreno do texto pré-estruturado (Macek, 2013) - a curadoria social requer a estratégia ativa de "puxar" a notícia, convidando o cidadão a pesquisar, filtrar, selecionar, organizar, interpretar, reenquadrar e finalmente distribuir os conteúdos coletados.

Um conjunto de plataformas especialmente voltadas à curadoria social emergiu nos últimos anos para permitir que as pessoas colecionem diferentes tipos de conteúdo, incluindo fotos, sons, vídeos e notícias. Um dos exemplos mais proeminentes destas plataformas é o PInterest, um site que permite aos usuários armazenar e categorizar imagens, que são denominadas "pinos" e organizadas em painés chamados pinboards. Um fato notável é que a pesquisa acadêmica existente sobre os sites de curadoria social de conteúdo tem sido quase exclusivamente dirigida ao site PInterest até aqui. Um olhar crítico sobre esse foco estreito é observar que, de todas as possíveis formas de curadoria social praticada online, a nossa compreensão desse fenômeno é amplamente informada estudando como as pessoas curam conteúdo no PInterest! O objetivo de muitos estudos sobre o PInterest parece ser uma melhor compreensão do site em si, ao invés do estudo da curadoria social como um fenômeno mais amplo. Poucos estudos comparam os sites de curadoria entre si, havendo uma oportunidade perdida de transferir esses achados para outros domínios de curadoria social pouco investigados e compreendidos.

Neste trabalho de pesquisa, o objetivo principal é endereçar duas lacunas de pesquisa. A primeira delas refere-se ao foco estreito da maioria dos estudos envolvendo as plataformas de curadoria social sobre alguns sites como o Pinterest. Em primeiro lugar, uma análise exploratória das plataformas de notícias sociais foi conduzida, sob a perspectiva da "Computação de Multidões" (Gomes et al., 2013; Moraes et al., 2014; Oliveira et al., 2015), em busca de desafios e questões de pesquisa (Padoa et al., 2015), que também produziu uma tipologia destas aplicações (Schneider, de Souza \& Lucas, 2014). Esta pesquisa inicial nos ofereceu uma oportunidade de pesquisa e design: os ambientes de notícias sociais.

A segunda lacuna de pesquisa diz respeito à carência de pesquisas construtivas dirigidas a plataformas de curadoria social. A forma como endereçamos esta segunda lacuna foi através da concepção de uma plataforma de computação social - chamada Acropolis - que permite aos cidadãos construir e compartilhar suas próprias narrativas sobre histórias noticiosas complexas ou de longa duração (como a "Operação Lava-Jato" ou o "Aquecimento Global"). O design do Acropolis foi orientado por um conjunto de questõeschave que foram identificadas através da revisão da literatura (Schneider \& de Souza, 2015).

Nesta pesquisa, sustentamos que o objetivo de engajar o cidadão na leitura e na curadoria de histórias noticiosas poderia ser endereçado através de um ambiente de mídia social que permitisse que cada usuário contribuísse com diferentes ângulos ou perspectivas de uma história em suas narrativas personalizadas. Usando a metodologia de "pesquisa através de design e ação", concluímos dois ciclos de design do Acropolis neste trabalho.

$\mathrm{O}$ restante deste artigo é organizado da seguinte forma. Na seção 2 descrevemos sucintamente a metodologia de pesquisa utilizada neste trabalho. Em seguida, na seção 3, abordamos o problema de engajar o cidadão em histórias noticiosas complexas ou 
de longa duração. Nas seções 4 e 5 descrevemos, respectivamente, a formulação do problema e o processo de construção, intervenção e avaliação da plataforma proposta, como preconizados pela metodologia ADR. Na seção 6 discutimos um subconjunto dos resultados obtidos de avaliações qualitativa e quantitativa realizadas no segundo ciclo de design - que correspondem à fase de reflexão e aprendizagem da ADR. Finalmente, concluímos o trabalho apresentando um conjunto de recomendações de design para a construção de plataformas semelhantes (seção 7) e as conclusões do artigo (seção 8).

\section{Metodologia de Pesquisa}

Este projeto de pesquisa foi conduzido como um case da ADR (Action Design Research), um método que combina a "pesquisa através de design” e a "pesquisa-ação" (Sein et al., 2011), e composto das seguintes etapas: 1) formulação do problema; 2) construção, intervenção e avaliação; 3) reflexão e aprendizagem; e 4) formalização da aprendizagem. Trata-se de uma metodologia baseada na "design science", comumente utilizada na pesquisa em SI (Crespo \& Santos, 2015). Por também ser baseada na pesquisa-ação, um elemento crucial na ADR é a interação entre pesquisadores e usuários implicados na situação investigada com o objetivo de resolver o problema-alvo da pesquisa (Colette \& Silva, 2014).

A exemplo de outros casos de aplicação da ADR, o projeto do Acropolis teve dois objetivos paralelos: fazer uma intervenção no espaço de design das plataformas de curadoria social de conteúdo noticioso (visando engajar os cidadãos em histórias complexas ou de longa duração) e criar conhecimento teórico ao colocarmos em prática e avaliarmos os princípios de design utilizados na construção da plataforma proposta (Figura 1).

No que se refere à formulação do problema (primeira fase da ADR), o projeto do Acropolis foi informado por uma literatura abrangente, descrita em um trabalho

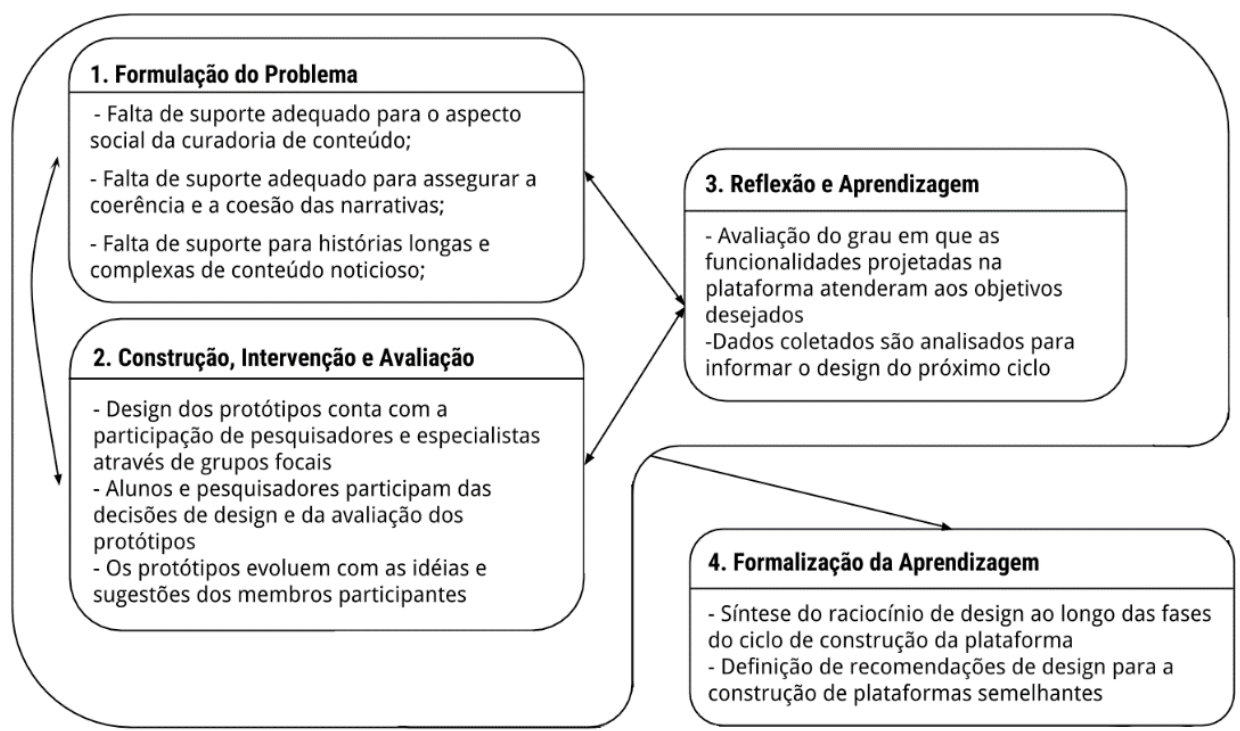

Figura 1 - Design do Acropolis através da ADR 
anterior (Schneider \& de Souza, 2015). No que diz respeito à segunda fase de construção, intervenção e avaliação (BIE), o projeto aderiu ao "design centrado no usuário", que coloca as necessidades dos usuários finais na linha de frente do design, tratando-os como informantes em várias atividades, sem exigir, porém, que eles estejam envolvidos nas decisões de design.

A terceira fase da ADR - reflexão e aprendizagem - foi conduzida através de contínua discussão e reflexão sobre a eficácia das decisões de design em endereçar o problema (refletidas nas diversas funcionalidades projetadas na plataforma), uma vez que em determinado ponto do processo cíclico da ADR, concentramos nossos esforços num conjunto de funcionalidades específico, ao qual deseja-se dar maior foco. Por último, na quarta e última fase da metodologia - a formalização da aprendizagem - articulamos um conjunto de recomendações de design que refletem o conhecimento adquirido ao longo do processo.

Em cada um dos ciclos de design e construção dos protótipos, realizamos um experimento e recolhemos e analisamos os dados obtidos para informar o design da plataforma no ciclo seguinte. Conduzimos dois grupos focais durante o processo de design e avaliação do Acropolis até o segundo ciclo (um grupo exploratório e outro confirmatório, respectivamente no primeiro e segundo ciclos de design).

\section{O problema de engajar o cidadão em histórias complexas ou de longa duração}

Na era do jornalismo rápido e instantâneo, dos orçamentos limitados, das reações imediatas no Twitter, e de preocupações sobre os efeitos deletérios da velocidade, Rob Orchard questiona - em seu TED Talk de outubro de 2014 - a que jornalista vai ser dado o tempo e o espaço para trabalhar em histórias complexas e de longa duração. A premissa sustentada por Orchard (2014) - entusiasta do chamado Jornalismo Slow - é que o jornalismo tradicional está obsoleto e precisa reinventar sua teoria e prática, a fim de permanecer relevante para uma nova cidadania. Esta cidadania evoluiu de uma audiência passiva, formada por pessoas que são meras consumidoras de notícias embaladas, para redes de usuários envolvidos ativamente, produtores e curadores de conteúdo noticioso em um ambiente de informação em rede a nível mundial (Milberry, 2006).

De acordo com Prior (2007), a fragmentação do conteúdo em inúmeros canais vem provocando a rejeição quase completa ao envolvimento por parte do cidadão com o conteúdo noticioso. Isto é particularmente verdadeiro para as gerações mais jovens, como apontado por Oeldorf-Hirsch (2011), que sustenta que os usuários mais jovens continuam desconectados da notícia. Nesse contexto, Yaros (2009) sustenta que duas perguntas importantes envolvem o "como" e o "porquê" os cidadãos vão se engajar em histórias complexas em um ambiente que oferece tantas opções de conteúdo.

Sustentamos que uma parcela importante desse problema (envolver o cidadão em histórias complexas, permitindo sua compreensão) se deve ao próprio modelo tradicional do jornalismo, que "fornece um primeiro rascunho, ao invés da versão final de uma história, deixando para os historiadores o processamento final dos eventos e materiais curados pelo jornalismo" (Zelizer, 2008). Lidar com o passado está além dos limites do que os jornalistas podem e devem fazer ao realizar seu trabalho, em função das próprias 
limitações de tempo associadas aos deadlines de uma redação. A própria questão da memória é vista como fora dos parâmetros da atenção dos jornalistas.

Por outro lado, fatores diversos podem afetar a habilidade de um indivíduo de compreender a informação, o que é ainda mais crítico em histórias noticiosas complexas. Em primeiro lugar, mera exposição à informação não é suficiente para que o aprendizado ocorra. A estrutura linear de escrita de uma história, que facilita sua compreensão pelos leitores, é ausente nas histórias tradicionais noticiosas que seguem a filosofia da "pirâmide invertida", que organiza as informações em ordem de importância percebida. Yaros (2005b) demonstrou como a simples organização dos fatos dentro de uma história complexa pode contribuir para uma compreensão mais profunda do seu conteúdo. Por exemplo, os efeitos se alteraram significativamente quando links de hipertexto foram adicionados às mesmas histórias (Yaros, 2005a). Neste ponto, Doherty (2013) argumenta que nem todas as histórias se encaixam na pirâmide invertida jornalística, e que o jornalismo cobre notícias de forma incremental: "histórias são produzidas ao longo do tempo e em torno de ângulos da notícia - várias perspectivas de uma história que, juntas, compõem a cobertura”. Finalmente, o trabalho de Gerodimos (2012), informado pelo trabalho de Yaros, sustenta a necessidade de investigação de formas inovadoras de storytelling que enfatizem a linha do tempo e o contexto, tornando o material acessível ao público não especializado.

Neste trabalho de pesquisa, sustentamos que engajar o cidadão na curadoria social de conteúdo noticioso, no contexto de um ambiente de curadoria social, pode ser um caminho para engajá-lo em histórias complexas ou de longa duração que estão no seu radar. O desafio de design é projetar as estruturas que permitam esse engajamento.

\subsection{Medindo o engajamento com o conteúdo noticioso}

Não há consenso na literatura sobre definições de engajamento com conteúdo noticioso. Alguns pesquisadores sustentam que o engajamento dos usuários com o conteúdo é uma composição de várias métricas de exposição e comportamentos interativos (Beckett, 2010).

Dito isto, a maioria dos trabalhos sobre engajamento de usuários no consumo de notícias tem empregado métricas simplistas de exposição (como visualização e compartilhamento de notícias na Web). Alguns pesquisadores associam o engajamento à extensão em que o usuário está disposto a investir seu tempo, esforço e atenção a determinado conteúdo (Brown \& Cairns, 2004). Outros pesquisadores como Yaros (2006) definem o engajamento como "interesse situacional" (que tem efeitos de curto prazo no indivíduo e é influenciado pelas características de um ambiente específico de aprendizagem), e que se diferencia do "interesse individual” (interesse ininterrupto em um domínio específico do conteúdo que se desenvolve ao longo do tempo e tende a ter efeitos duradouros nos valores e no conhecimento do indivíduo).

Nesta pesquisa aderimos ao arcabouço proposto por Ksiazek et al. (2014), que definem o engajamento (do usuário com o conteúdo) através de um continuum que varia do extremo de menor engajamento (métricas de exposição), passando pelos indicadores de popularidade, até o extremo de maior engajamento (métricas de interatividade). Os mesmos autores distinguem dois tipos de interatividade (usuário-conteúdo e usuário- 
usuário), sustentando que as interações com maior frequência e qualidade indicam um engajamento mais profundo. Enquanto a ação de "visualizar" é uma medida clássica de exposição a um conteúdo, indicadores de popularidade (avaliar, ranquear, curtir ou marcar como favorito) sugerem um nível de experiência do usuário que envolve alguma ação por parte do mesmo (Deuze, 2003).

Por outro lado, a prática de publicar uma opinião ou reação em resposta a uma notícia (por exemplo, comentários no ambiente online) sugere um indivíduo mais investido, consciente e atento, ou seja, "um usuário ativo que está desafiando, apoiando, ou pelo menos refletindo sobre a notícia” (Ksiazek et al., 2014). Em outras palavras, um usuário mais engajado com o conteúdo.

A relevância dos estudos que investigam mecanismos para medir e encorajar os comportamentos de engajamento com o conteúdo se justifica: altos níveis de engajamento interativo com a notícia podem ser sinal de cidadãos mais ativos. Além disso, considerando a perspectiva das organizações de notícias que desejam atrair usuários, evidência de usuários mais engajados com o conteúdo noticioso pode sinalizar maior potencial de assinantes pagos, bem como taxas de publicidade mais lucrativas (Hayes, 2008).

\section{Formulação do Problema}

O problema central que motivou esta "pesquisa através de design" pode ser formulado assim: "Como um aplicativo da Web Social pode engajar os cidadãos, especialmente as gerações mais jovens, em histórias noticiosas complexas, através da abordagem de curadoria social?" Os principais objetivos do esforço de pesquisa atual incluíram abordar as questões sintetizadas na Tabela 1, que mostra o problema, o contexto, uma demonstração encontrada na literatura ou em artefatos da Web, e a fonte.

\begin{tabular}{|c|c|c|c|}
\hline Problema & Contexto & Demonstração & Fonte \\
\hline $\begin{array}{l}\text { Falta de suporte adequado } \\
\text { para o aspecto social da } \\
\text { curadoria de conteúdo }\end{array}$ & $\begin{array}{l}\text { Plataformas de } \\
\text { curadoria social }\end{array}$ & $\begin{array}{l}\text { "Nossos estudos de usuários revelam } \\
\text { que a maioria dos usuários vê a } \\
\text { curadoria como uma atividade } \\
\text { pessoal, em vez de social." }\end{array}$ & $\begin{array}{l}\text { Zhong et al. } \\
\text { (2013) }\end{array}$ \\
\hline $\begin{array}{l}\text { Falta de suporte adequado } \\
\text { para assegurar a coerência e a } \\
\text { coesão das narrativas }\end{array}$ & $\begin{array}{l}\text { Plataformas de } \\
\text { curadoria social }\end{array}$ & $\begin{array}{l}\text { “Estou preocupado que o resultado } \\
\text { final são 'frankenhistórias' [...] que são } \\
\text { ajuntadas, de forma anárquica, sem } \\
\text { elegância ou fluxo narrativo” (sobre o } \\
\text { site Storify) }\end{array}$ & $\begin{array}{l}\text { Garber } \\
(2010)\end{array}$ \\
\hline $\begin{array}{l}\text { Falta de suporte para histórias } \\
\text { longas de conteúdo noticioso }\end{array}$ & Jornais online & $\begin{array}{l}\text { “A que jornalista será dado o tempo e } \\
\text { o espaço para trabalhar em histórias } \\
\text { complexas e de longa duração?” }\end{array}$ & $\begin{array}{l}\text { Orchard } \\
(2014)\end{array}$ \\
\hline
\end{tabular}

Tabela 1 - Questões relacionadas à tecnologia de curadoria social de notícias mencionadas na literatura e em artefatos da Web

No primeiro ciclo de design, nós escolhemos o nicho de aplicação das histórias políticas ao testar o protótipo do Acropolis, acreditando que essa escolha seria oportuna. Argumentamos que esta escolha foi acertada, motivando os participantes que estiveram envolvidos no experimento. O primeiro ciclo de design é descrito em (Schneider \& de Souza, 2015). 
No segundo ciclo de design, ampliamos o foco das narrativas retratadas pelos usuários incluindo também outros tipos de histórias, além daqueles de natureza política, o que foi enfatizado pelo slogan exibido na página inicial da plataforma: "Fale sobre política, economia e meio ambiente sem ser um político, economista ou ecologista”.

\section{Construção, Intervenção e Avaliação}

Com base neste contexto de pesquisa, projetamos o primeiro protótipo do Acropolis, avaliado através de um experimento descrito em (Schneider \& de Souza, 2015). Para cada usuário, a plataforma apresenta uma página inicial (Figura 2A), que permite ao usuário acompanhar as histórias em que é um leitor ou curador; manter uma lista das figuras públicas sendo monitoradas; manter a rede social do usuário. Em outra página do sistema, o usuário pode navegar e curar histórias de seu interesse (Figura 2B). Há também uma página dedicada a figuras públicas, onde o usuário pode registrar ou editar o perfil de comunicadores estratégicos (políticos, jornalistas, etc.) que o usuário tem interesse em seguir.

\subsection{Abordagem de curadoria}

Na abordagem embutida no Acropolis, o usuário pode ser um leitor ou um curador de uma determinada história. Se ele é apenas um leitor, então ele visualiza a "narrativa pública” da história - que contém as contribuições dos vários curadores da história - e as narrativas pessoais de cada curador. Se o usuário desejar ser curador de uma história, então ele pode criar a sua própria narrativa pessoal. Na construção de uma narrativa de uma determinada história, conteúdos que foram curados por outros curadores da história são sugeridos para o usuário, dando crédito aos curadores anteriores.

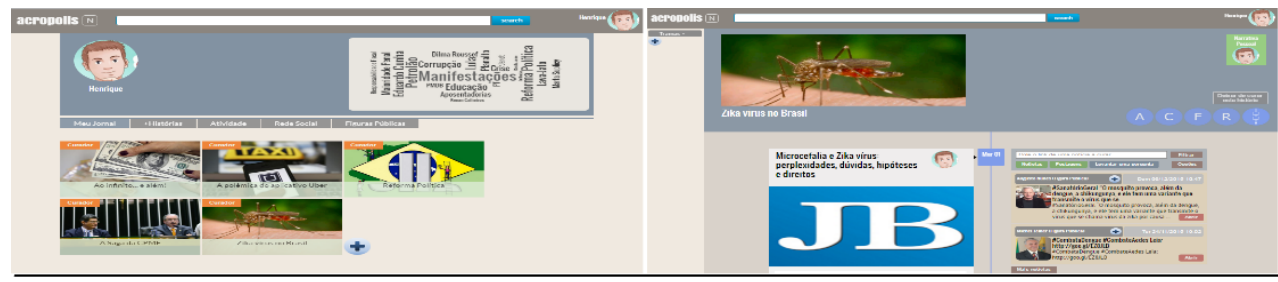

Figura 2 - Duas telas do Acropolis. A) Esquerda: interface do "Meu Jornal”; B) Direita: lendo e curando uma narrativa

As narrativas do Acropolis são, portanto, remixáveis. O mecanismo de curar e "recurar" conteúdos (a partir de outras narrativas) facilita e agiliza a construção das narrativas pessoais dos vários curadores de uma história, permitindo que a curadoria social emirja da experiência de compartilhamento de peças de conteúdo coletadas. Uma vez que a leitura e a curadoria são impactadas pelas respectivas ações de outros usuários, a plataforma oferece uma experiência social encorajadora.

O primeiro passo para o curador construir uma narrativa é buscar conteúdos dentro ou fora da plataforma. A seleção e a coleta de conteúdos são feitas usando operações simples de arrastar e soltar. Ao adicionar conteúdo a uma narrativa pessoal, o curador enfatiza sua perspectiva particular (adicionando um título e uma descrição). A plataforma oferece 
três alternativas para curar conteúdos: curar conteúdo para a história, curar conteúdo "em resposta" a outro conteúdo previamente curado na história, e curar conteúdo como uma “alternativa” a um conteúdo já curado (Schneider \& de Souza, 2015).

Ainda no design preliminar dos protótipos, foram concebidas diversas opções para o usuário para adicionar conteúdo às suas narrativas: digitando a URL de uma notícia ou vídeo a ser curado; curando notícias, vídeos ou mensagens de figuras públicas sugeridos pela plataforma; recurando conteúdos previamente curados por outros usuários; ou buscando conteúdos dentro da plataforma (a fim de serem coletados). É importante salientar que o Acropolis apoia os usuários na navegação e na construção de suas narrativas, exibidas através de "linhas do tempo" horizontais ou verticais. Além disso, a plataforma oferece uma facilidade de "narração", que permite "reproduzir" uma narrativa (Schneider \& de Souza, 2015) e possibilita uma melhor compreensão da história por parte dos leitores e curadores.

Assim, o modelo de curadoria ao Acropolis segue essencialmente as fases do "ciclo de aprendizagem da pesquisa curatorial” (Wolff \& Mulholland, 2013), começando com a pesquisa, seguida da seleção e coleta do conteúdo, seguida da interpretação do conteúdo individual e de um grupo de conteúdos, seguida da organização do conteúdo e de suas anotações e, finalmente, seguida da narração.

\subsection{Segundo ciclo de design}

Depois de finalizado o primeiro ciclo, onde concluímos o design, o desenvolvimento e o teste do primeiro protótipo, utilizamos o conhecimento obtido ao término do ciclo para conduzir o design do segundo protótipo. Uma preocupação que foi enfatizada nas entrevistas do primeiro ciclo refere-se à alternância entre a visualização das narrativas pessoais dos curadores, e pública, considerada confusa para a quase totalidade dos participantes. Nós redesenhamos quase que por completo essa facilidade no sistema, simplificando essa ação para o usuário.

No segundo ciclo também buscamos aprimorar consideravelmente a usabilidade bem como a amigabilidade do sistema. Por exemplo, operações de curadoria como "curar como resposta" não haviam sequer sido exploradas no primeiro ciclo, ação esta que permite ao usuário colaborar na narrativa pessoal de outro usuário (colaboração assimétrica). Por último, buscamos avaliar o impacto da introdução de elementos de jogos (gamificação) no curso do experimento conduzido neste segundo ciclo.

\subsection{Coleta de dados}

Para testar o nosso segundo protótipo, convidamos os 12 alunos da disciplina de "Trabalho Cooperativo Suportado por Computador” do curso de Pós-Graduação do PESC/COPPE/ UFRJ (ano de 2015) para utilizar o protótipo do Acropolis. Os participantes usaram o Acropolis durante 14 dias, e ao término do experimento, responderam a um questionário e participaram de uma entrevista pessoal.

Os participantes foram convidados a contribuir diariamente na curadoria de conteúdo para histórias de interesse. De modo análogo ao que havia sido feito no experimento do primeiro ciclo, enviamos um lembrete diário por email durante o estudo, lembrando aos participantes de adicionar mais conteúdo. Além disso, no email diário frequentemente reportávamos as novas funcionalidades (como os incentivos de gamificação, que foram liberados gradualmente) ou incluíamos dicas ou sugestões para estimular a contribuição. 
Cada entrevista levou cerca de meia hora, e o conjunto das entrevistas nos permitiu obter uma melhor compreensão do uso dos recursos projetados na plataforma.

\section{Reflexão e Aprendizagem}

Enquanto o ciclo 1 de design do Acropolis concentrou-se na coleta de dados exploratórios qualitativos, no ciclo 2 a avaliação realizada mesclou dados tanto qualitativos quanto quantitativos.

\subsection{Demografia e contribuições na curadoria de histórias}

Dentre os participantes do experimento, nove eram estudantes do sexo masculino, e três eram estudantes do sexo feminino, como ilustra a Tabela 2. Onze eram alunos de mestrado e um participante era estudante de doutorado; dez alunos tinham graduação em Ciência da Computação ou Engenharia de Computação ou Sistemas de Informação, e dois alunos tinham formação básica em Engenharia Eletrônica.

\begin{tabular}{|c|c|c|c|c|c|c|c|}
\hline ID & Sexo & Dias & Hist. lidas & Hist. curadas & Curados & Comentários & Perguntas \\
\hline P1 & M & 12 & 13 & 5 & 85 & 4 & 1 \\
P2 & M & 10 & 12 & 4 & 12 & 14 & 3 \\
P3 & M & 6 & 14 & 14 & 53 & 1 & 1 \\
P4 & M & 13 & 6 & 2 & 25 & 10 & 1 \\
P5 & F & 14 & 24 & 18 & 178 & 5 & 4 \\
P6 & M & 9 & 7 & 2 & 6 & 3 & 1 \\
P7 & M & 10 & 25 & 17 & 298 & 28 & 5 \\
P8 & M & 11 & 25 & 25 & 548 & 97 & 5 \\
P9 & F & 12 & 18 & 13 & 211 & 20 & 3 \\
P10 & M & 11 & 5 & 3 & 30 & 2 & 0 \\
P11 & F & 10 & 15 & 10 & 29 & 2 & 0 \\
P12 & M & 11 & 26 & 22 & 557 & 109 & 15 \\
\hline
\end{tabular}

Tabela 2 - Resumo da demografia dos participantes e participação no experimento

A tabela mostra que os participantes variaram no número de dias em que utilizaram a plataforma, no número de histórias lidas e curadas, bem como no total de contribuições (ilustradas nas últimas três colunas através do número de conteúdos curados, do número de comentários postados, e do número de perguntas levantadas).

\subsection{Avaliação qualitativa}

Como já enfatizado, ao término do experimento conduzido durante o segundo ciclo de design do Acropolis, além de responderem a um questionário, os participantes participaram de uma entrevista que, combinada com dados também obtidos dos questionários, permitiram-nos conduzir uma avaliação qualitativa das experiências com o protótipo. A reflexão sobre essa avaliação é discutida nos tópicos que serão apresentados a seguir.

\section{A. Abordagem da plataforma e experiência geral de uso}

$\mathrm{O}$ primeiro ponto que procuramos abordar nas entrevistas diz respeito à abordagem de curadoria proposta na plataforma. Perguntamos aos participantes como eles avaliaram a abordagem do Acropolis de orientar a curadoria de conteúdo em torno de histórias de natureza noticiosa criadas pelos próprios usuários. 
Todos os 12 participantes avaliaram positivamente a abordagem do Acropolis, ainda que 3 deles ( $\mathrm{P}_{4}, \mathrm{P} 6$ e P12) tenham feito algumas ressalvas. Dentre os principais pontos positivos destacados pelos participantes estão a possibilidade de cada usuário contar sua própria versão das histórias acrescentando sua opinião às notícias curadas, o acesso a diferentes visões de uma mesma história, a liberdade de direcionar assuntos de maior interesse dentro de cada história, e o acesso a assuntos e eventos noticiosos com pouca ou nenhuma cobertura da grande mídia. Este último ponto foi ilustrado pelo participante P5: "No caso da história do Swiss Leaks, não tinha nem passado por mim esse assunto. Alguém criou (uma história dedicada ao tema no Acropolis), e fui procurar a respeito e buscar notícias também".

Alguns participantes salientaram a importância da "pauta" montada pelos próprios usuários, como pode ser notado na declaração do participante $\mathrm{P}_{5}$ : “A mídia tende a ter uma pauta muito centrada em determinados assuntos que eles querem tratar $e$ evidenciar. No Acropolis, nós é que fazemos o nosso jornal com os nossos assuntos e interesses". Por outro lado, o participante $\mathrm{P} 7$ enalteceu especificamente o recurso de "criar histórias" na plataforma (definindo-se título, figura de fundo e palavras-chaves), já que "criando um título interessante para falar de um determinado assunto, você pode atrair mais gente pra ler aquela história”.

O participante $\mathrm{P} 4$ questionou se a abordagem seria eficaz caso muitos usuários estivessem colaborando numa mesma história. Foi informado a este participante que, num cenário de colaboração massiva envolvendo um número potencialmente grande de curadores, cada usuário só iria visualizar as contribuições (numa determinada história) dos usuários que ele adicionasse à sua rede de pessoas "seguidas". O participante P6 considerou positiva a abordagem do Acropolis, ao mesmo tempo que demonstrou ter ficado confuso ao navegar e tentar contribuir nas histórias: "O que eu mais fiz foi ler as notícias. Eu fiquei um pouco perdido na plataforma, mas confesso que não fui um dos que mais participei. Eu tinha receio de chegar no meio da conversa, e não saber onde estava exatamente (a história)". Foi informado a este participante que ele poderia ter explorado o feed de atividade da história, que mostrava exatamente o desenrolar das contribuições de cada participante numa determinada história. Por último, o participante P12 confessou estar mais habituado a um tipo de consumo passivo das notícias: "Eu prefiro a abordagem do RSS, na qual você se inscreve pro tipo de notícia que você mais gosta, e você recebe os feeds de tempos em tempos. Mas a abordagem do Acropolis atendeu bem também, porque eu entrava e lia as notícias e histórias que me interessavam".

\section{B. Participação}

Ao longo dos 14 dias do experimento, foram construídas 137 narrativas pessoais de um total de 26 histórias criadas pelos próprios participantes (Tabela 3). Das vinte e seis histórias, somente uma delas não se encaixou no critério de ser uma história "complexa ou de longa duração".

Para avaliar o grau em que os participantes se envolveram nas principais funcionalidades e usos da plataforma, elaboramos uma consulta abrangente ao log das ações dos usuários (armazenado no banco de dados da plataforma), considerando as seguintes ações: logar na plataforma; ler os conteúdos de uma história; curar conteúdos para alguma história; comentar algum conteúdo; levantar uma pergunta. Os resultados foram utilizados para gerar 
um gráfico de visualização da participação dos 12 participantes nos 14 dias do experimento, ilustrado na Figura 3. A figura apresenta uma notação especial para representar as ações (ou combinações de ações), sintetizada na legenda à direita da própria figura.

Ao observarmos este gráfico, é possível tirar algumas conclusões importantes. Excetuando-se os participantes $\mathrm{P}_{3}$ e P6, os outros dez participantes tiveram uma participação ativa na plataforma. $\mathrm{O}$ participante $\mathrm{P} 3$ utilizou a plataforma em somente 6 dos 14 dias do experimento, e em apenas metade desses dias ele curou conteúdo (nos outros dias ele foi apenas leitor). Já o participante P6 utilizou a plataforma durante 9 dias, e curiosamente deixou de curar conteúdos do $4^{\circ}$ dia de uso em diante, o que vai ao encontro do relatado por ele na entrevista.

De modo geral, a predominância dos círculos azuis (em relação aos círculos verdes) salienta que o comportamento mais comum dos usuários era participarem não apenas comoleitores, mas como curadores das histórias, ainda que o gráfico não ilustre a quantidade de histórias lidas e curadas por dia. Em maior ou menor grau, todos os participantes envolveram-se em algum debate em torno das histórias - tanto através de comentários (ilustrados pelo fundo em vermelho nos círculos), quanto através de perguntas que eles levantaram ao longo do experimento. Basta ver que todos os doze participantes contribuíram com algum comentário, e somente 2 dos 12 participantes não levantaram perguntas.
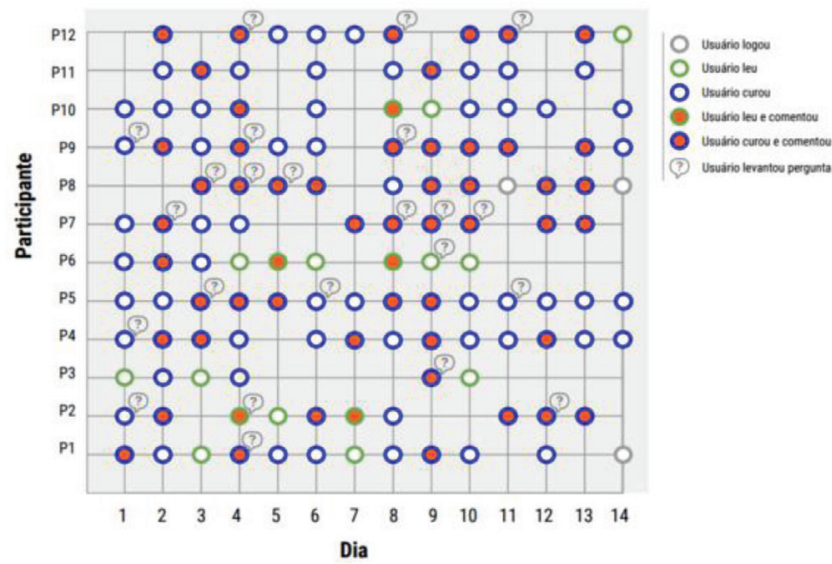

Figura 3 - Panorama de participação do experimento do $2^{\circ}$ ciclo de design do Acropolis

O grau de participação dos usuários na atividade de curadoria é ilustrado na Figura 4, que exibe o total de conteúdos curados por cada participante. Tal gráfico é bem representativo do que os pesquisadores de computação social chamam de "lei de potência de participação": um grupo pequeno de usuários faz o "serviço", e a grande maioria não tem um grande envolvimento, assumindo o papel de free riders ("parasitas"), tomando "carona" em cima do trabalho produzido pelos outros. Como complemento a este gráfico, $54 \%$ dos conteúdos curados durante o experimento foram coletados por somente dois usuários (P8 e P12), e 95\% dos conteúdos curados foram coletados por metade dos participantes (a outra metade junta coletou menos de $5 \%$ dos conteúdos). 


\subsection{Avaliação quantitativa}

Uma das ambições iniciais da pesquisa através de design conduzida neste trabalho era avaliar a participação no sistema implementado em termos do engajamento dos usuários com o conteúdo das histórias. Fizemos uma avaliação quantitativa do engajamento percebido, centrado no usuário, e descrito em (Schneider \& de Souza, 2016), que trouxe resultados promissores. O objetivo desta seção é fornecer uma medida do engajamento dos usuários tendo a mídia em si como parâmetro - ou seja, medir o engajamento centrado nas histórias. A ideia, portanto, é analisar o conjunto das histórias curadas em termos do engajamento dos usuários com as mesmas, de acordo com os critérios de exposição, popularidade e interatividade do arcabouço proposto por Ksiazek et al. (2014).

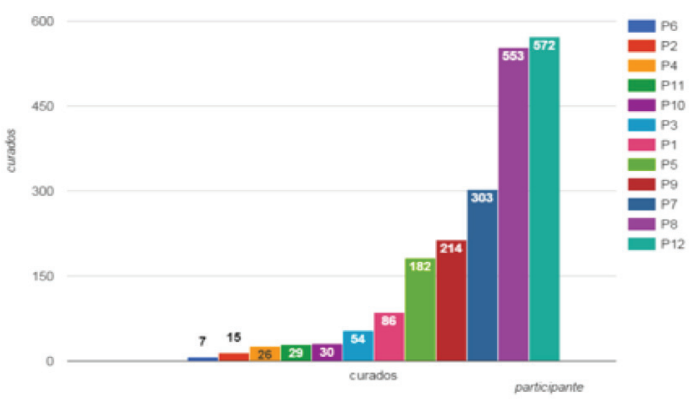

Figura 4 - Total de conteúdos curados pelos participantes do experimento do $2^{\circ}$ ciclo de design do Acropolis

A unidade de análise deste estudo de engajamento é a "história", de forma que as métricas foram medidas para cada história, e não para cada conteúdo (notícia, vídeo, postagem) individualmente. A fim de medir a exposição de cada história, usamos o número de visualizações da mesma; para medir a popularidade, usamos o número de avaliações e de ações de "recuradoria"; e para medir o nível de interatividade, usamos o número de comentários postados sobre os conteúdos da história. Apesar de não constar do arcabouço proposto por Ksiazek et al. (2014), achamos útil acrescentar a métrica "total de conteúdos recurados" na avaliação aqui proposta. Sustentamos que o número de conteúdos recurados expressa uma forma de engajamento associada ao grau em que os usuários recorrem aos seus pares em suas decisões de curadoria.

A Tabela 3 ilustra as métricas de engajamento computadas para o conjunto de 26 histórias curadas durante o segundo experimento (ordenadas em ordem decrescente do total de conteúdos curados). A tabela informa, além do código e título de cada história, o total de curadores, leitores, visualizações, conteúdos curados, conteúdos recurados, avaliações (dos conteúdos da história), e comentários (sobre os conteúdos da história).

Na última linha da tabela computamos o coeficiente de correlação de Pearson ( $\rho$ ) para as quatro últimas variáveis, comparando-as com o total de visualizações da história. Observamos que o total de conteúdos curados tem correlação altíssima com o total de visualizações $(\rho=0.95)$, e o mesmo acontece com o total de comentários $(\rho=0.80)$. O total 
de conteúdos recurados e de avaliações também possuem uma correlação expressiva com o total de visualizações, porém mais modesta do que as anteriores (respectivamente $\rho=0.64$ e $\rho=0.65$ ).

A relação positiva entre a métrica de engajamento por exposição (total de visualizações) e a métrica de engajamento interativo (total de comentários) - expressa pela alta correlação entre as duas - traz fortes evidências de que a popularidade de uma história do Acropolis poderia ser inferida a partir do engajamento interativo dos usuários com o conteúdo. Isso traz implicações positivas do ponto de vista das organizações de notícias, que poderiam explorar o grau de interatividade dos usuários com as histórias como preditor da popularidade de uma história!

\begin{tabular}{|c|c|c|c|c|c|c|c|c|}
\hline \#id & História & curadores & leitores & visualizaçōes & curados & recurados & avaliaçōes & comentários \\
\hline 28 & Enem & 4 & 7 & 829 & 249 & 17 & 0 & 49 \\
\hline 15 & Operaçấo Lava Jato & 7 & 9 & 526 & 227 & 82 & 19 & 15 \\
\hline 16 & Ao infinito e alem! & 8 & 12 & 685 & 172 & 87 & 17 & 28 \\
\hline 17 & Olimpiadas Rio 2016 & 8 & 11 & 508 & 148 & 37 & 15 & 33 \\
\hline 18 & O jogo do impeachment & 7 & 9 & 508 & 115 & 34 & 12 & 12 \\
\hline 19 & Reduça da idade penal & 8 & 13 & 240 & 97 & 35 & 4 & 4 \\
\hline 27 & Greve nas universidades federais & 6 & 9 & 260 & 97 & 35 & 2 & 26 \\
\hline 20 & Desemprego no Brasil - O pior resultado em 11 anos & 6 & 9 & 260 & 84 & 20 & 8 & 13 \\
\hline 25 & A politica e a espionagem: NSA espionou... & 4 & 9 & 179 & 79 & 27 & 1 & 18 \\
\hline 24 & Reforma Politica & 6 & 8 & 167 & 73 & 36 & 1 & 3 \\
\hline 31 & Crise na segurança pública & 5 & 6 & 211 & 68 & 19 & 0 & 3 \\
\hline 21 & Swiss Leaks: Crimes do colarinho branco & 4 & 8 & 240 & 67 & 32 & 8 & 7 \\
\hline 22 & Crise na base aliada do governo & 5 & 7 & 146 & 66 & 18 & 6 & 1 \\
\hline 32 & A tecnologia atualizando o crime & 6 & 7 & 192 & 64 & 32 & 5 & 18 \\
\hline 37 & Impostômetro & 4 & 5 & 148 & 63 & 26 & 0 & 3 \\
\hline 33 & A Saúde no Brasil & 6 & 7 & 172 & 62 & 17 & 1 & 2 \\
\hline 26 & Mesmo com crise, montadoras anunciaram R\$ $9 \mathrm{bi} . .$. & 6 & 6 & 123 & 58 & 23 & 0 & 13 \\
\hline 23 & A pollemica do aplicativo Uber & 7 & 10 & 163 & 57 & 29 & 3 & 19 \\
\hline 34 & O Sistema politico brasileiro & 5 & 7 & 144 & 51 & 27 & 2 & 17 \\
\hline 30 & Porque o Brasil nå inova & 5 & 6 & 159 & 46 & 12 & 2 & 3 \\
\hline 40 & Economia de Baixa Carbono & 3 & 4 & 70 & 33 & 7 & 0 & 0 \\
\hline 35 & Midia: Informaçăo ou Manipulaçăo? & 3 & 5 & 131 & 29 & 8 & 1 & 5 \\
\hline 38 & CPI da CBF & 5 & 6 & 82 & 25 & 3 & 0 & 0 \\
\hline 39 & BRICs e a Economia Mundial & 2 & 3 & 56 & 23 & 7 & 0 & 2 \\
\hline & Avaliaçåo do Governo Brasileiro & 4 & 6 & 58 & 15 & 9 & 0 & 1 \\
\hline \multirow[t]{3}{*}{41} & Crise economica no mundo & 1 & 3 & 15 & 3 & 0 & 0 & 0 \\
\hline & Totais & & & 6272 & 2071 & 679 & 107 & 295 \\
\hline & Coeficiente de correlaçáo de Poarson ( $\rho$ ) & & & & 0.95 & 0.64 & 0.65 & 0.80 \\
\hline
\end{tabular}

Tabela 3 - Métricas de engajamento do usuário com o conteúdo das histórias

Outra evidência positiva é que o número expressivo de 295 comentários postados - uma medida do engajamento interativo - sugere um nível de engajamento mais profundo por parte dos usuários. Apesar de estatisticamente pouco representativa, a quantidade de avaliações recebidas pelos conteúdos de uma história - que também trouxe uma relação positiva com a métrica de exposição - expressa uma forma de engajamento associada à "recomendação", enfatizando as histórias mais bem recomendadas pelos usuários leitores e curadores. Sustentamos ainda que a métrica do número de conteúdos recurados - associada à medida em que os usuários confiam nos seus contatos para suas decisões de gatekeeping - também apresentou evidências de relação positiva com a métrica de exposição, uma questão que sem dúvida merece ser melhor investigada em trabalhos futuros.

\section{Formalização da Aprendizagem (Ciclo 2)}

Pesquisa orientada a design deve indicar a que classe de problemas de design seus achados e conclusões podem ser generalizados, a fim de estabelecer uma contribuição para a pesquisa. A classe de problemas é definida aqui como "plataformas de curadoria social para contar histórias noticiosas”. Nesta seção, listamos um conjunto de recomendações de design que consideramos generalizáveis a esta classe de sistemas. 
Uma lista preliminar destas recomendações foi consolidada ao final do primeiro ciclo de design - e apresentadas em (Schneider \& de Souza, 2015) - e estendidas ao final do segundo ciclo. Em decorrência disso, nos limitaremos aqui a discutir somente a última recomendação.

Recomendação 1: Utilize as histórias compartilhadas como mecanismo para reunir os itens curados

Recomendação 2: Incentive os usuários a construir suas narrativas com a ajuda de seus pares para permitir a variação em perspectiva

Recomendação 3: Incentive os usuários a "recurar" contribuições relevantes

Recomendação 4: Siga histórias, não as pessoas

Recomendação 5: Contemplar os comunicadores estratégicos é fundamental

Recomendação 6: Narrativas pessoais curadas pelo usuário

A construção de narrativas curadas pelo usuário como uma estratégia de elaboração foi considerada bem-sucedida no design do Acropolis, possibilitando que os usuários se engajassem nas histórias, e isso foi comprovado através de várias evidências positivas na avaliação do experimento do segundo ciclo de design. Neste contexto, a recomendação é projetar os ambientes de curadoria de conteúdo noticioso suportando as "narrativas curadas pelo usuário", dando liberdade aos participantes de escolher as histórias em que desejam contribuir, e incentivando-os a reenquadrar os conteúdos e construir suas narrativas remixando conteúdos das narrativas dos outros particicipantes.

\section{Conclusão}

Neste artigo, descrevemos o segundo ciclo de design e avaliação do Acropolis, uma plataforma de computação social que permite aos cidadãos construir e compartilhar suas próprias narrativas sobre histórias de conteúdo noticioso, envolvendo-os em um processo de curadoria social. Resultados obtidos através de avaliações qualitativa e quantitativa demonstraram que a tecnologia de curadoria social pode ser promovida como uma forma de endereçar o problema de engajar as futuras gerações com o conteúdo noticioso, validando positivamente as decisões de design descritas em trabalhos anteriores. Seguindo a metodologia ADR, concluimos os dois primeiros ciclos deste trabalho de pesquisa com um conjunto de recomendações de design para a construção de plataformas semelhantes.

\section{Referências}

Abreu, A., Rocha, Á., de Carvalho, J. V., \& Cota, M. P. (2016). The electronic booklet on teaching-learning process: Teacher vision and parents of students in primary and secondary education. Telematics and Informatics, August 12.

Beckett, L. (2010). Getting beyond just pageviews: Philly. com's seven-part equation for measuring online engagement. Nieman Journalism Lab. 
Brown, E., \& Cairns, P. (2004, April). A grounded investigation of game immersion. In CHI'O4 extended abstracts on Human factors in computing systems (pp. 12971300). ACM.

Colette, M. M., \& Silva, M. H. C. D. (2014). Novos cenários de aprendizagem, inovação e sustentabilidade: Uma pesquisa-ação na graduação em Ciências e Tecnologia. RISTI - Revista Ibérica de Sistemas e Tecnologias de Informação, (SPE2), 55-69.

Crespo, P., \& Santos, V. (2015). Construction of integrated business management systems for micro and small enterprises/Construcao de sistemas integrados de gestao para micro e pequenas empresas. RISTI - Revista Ibérica de Sistemas e Tecnologias de Informação, (15), 35-50.

Deuze, M. (2003). The web and its journalisms: considering the consequences of different types of newsmedia online. New media \& society, 5(2), 203-230.

Doherty, S. (2013). Hypertext and news stories (No. 2013-03, pp. 1-10). School of Information Technology and Electrical Engineering.

Garber, M. (2010). Meta! Here’s how Storify looks telling the story of Storify. Nieman Journalism Lab.

Gerodimos, R. (2012). Journalism students as global citizens and mediators: incorporating global current affairs into the journalism curriculum. Journalism.

Gomes, C., Schneider, D., de Souza, J., \& Xexéo, G. (2013, June). Cassino musical: A game with a purpose for social recruitment and measurement of musical talent. In Computer Supported Cooperative Work in Design (CSCWD), 2013 IEEE 17th International Conference on (pp. 593-598). IEEE.

Hayes, T. (2008). Jump point: How network culture is revolutionizing business. McGraw-Hill, Inc.

Jenkins, H., Ford, S., \& Green, J. (2013). Spreadable media: Creating value and meaning in a networked culture. NYU press.

Ksiazek, T. B., Peer, L., \& Lessard, K. (2014). User engagement with online news: Conceptualizing interactivity and exploring the relationship between online news videos and user comments. New media \& society, 1461444814545073.

Macek, J. (2013). More than a desire for text: Online participation and the social curation of content. Convergence: The International Journal of Research into New Media Technologies, 1354856513486530.

Milberry, K. M. (2006). Gatewatching: Collaborative online news production. Canadian Journal of Communication, 31(3).

Moraes, A. L. D., Fonseca, F., Esteves, M. G. P., Schneider, D., \& de Souza, J. M. (2014, May). A meta-model for crowdsourcing platforms in Data Collection and Participatory Sensing. In Computer Supported Cooperative Work in Design (CSCWD), Proceedings of the 2014 IEEE 18th International Conference on (pp. 429-434). IEEE. 
Oeldorf-Hirsch, A. (2011). Engagement with news content in online social networks (Doctoral dissertation, The Pennsylvania State University).

Oliveira, L. F., Schneider, D., de Souza, J. M., \& Rodrigues, S. A. (2015, May). Leveraging the crowd collaboration to monitor the waiting time of day-to-day services. In Computer Supported Cooperative Work in Design (CSCWD), 2015 IEEE 19th International Conference on (pp. 109-114). IEEE.

Orchard, R. (2014). The Slow Journalism Revolution. YouTube video. Posted by "TEDx Talks." Oct, 13.

Padoa, C., Schneider, D., De Souza, J. M., \& Medeiros, S. P. J. (2015, May). Investigating social curation websites: A crowd computing perspective. In Computer Supported Cooperative Work in Design (CSCWD), 2015 IEEE 19th International Conference on (pp. 253-258). IEEE.

Prior, M. (2007). Post-broadcast democracy: How media choice increases inequality in political involvement and polarizes elections. Cambridge University Press.

Schneider, D., \& De Souza, J. (2015). Engaging citizens with news stories through social curation: a design research project. In 14th Brazilian Symposium on Human Factors in Computing Systems.

Schneider, D., \& de Souza, J. Exploring asymmetric collaboration in social news curation. In 2016 IEEE International Conference on Systems, Man, and Cybernetics (SMC). IEEE.

Schneider, D., de Souza, J., \& Lucas, E. M. (2014, October). Towards a typology of social news apps from a Crowd Computing perspective. In 2014 IEEE International Conference on Systems, Man, and Cybernetics (SMC) (pp. 1134-1140). IEEE.

Sein, M., Henfridsson, O., Purao, S., Rossi, M., \& Lindgren, R. (2011). Action design research. MIS Quarterly, 35(1), 37-56.

Wolff, A., \& Mulholland, P. (2013, May). Curation, curation, curation. In Proceedings of the 3rd Narrative and Hypertext Workshop (p. 1). ACM.

Yaros, R. A. (2005a). Building a Coherent Web: Using Structure Building Text and Hypertext to Facilitate Engagement and Understanding of News About Complex Issues. Association for Education in Journalism \& Mass Communication, San Antonio, TX.

Yaros, R. A. (2005b). Communicating complex news: Structuring stories to enhance public engagement and understanding of science. 